This is the postprint of the original article published in Applied Physics A (2015) 118:457-463. The final publication is available at Springer http://dx.doi.org/10.1007/s00339-014-8645-3

\title{
MICRO-FADING SPECTROMETRY: INVESTIGATING THE WAVELENGTH SPECIFICITY OF FADING
}

\author{
Andrew Lerwill ${ }^{\mathrm{a}, \mathrm{c}, \mathrm{d},{ }^{*}}$, Anna Brookes ${ }^{\mathrm{b}}$, Joyce H. Townsend ${ }^{\mathrm{c}}$, Stephen Hackney ${ }^{\mathrm{c}}$, Haida Liang ${ }^{\mathrm{d}}$ \\ ${ }^{a}$ Getty Conservation Institute, 1200 Getty Center Drive; Suite 700, Los Angeles, USA \\ ${ }^{b}$ The National Archives, Kew Richmond, Surrey TW9 4DU, UK \\ ${ }^{c}$ Conservation Department, Tate, Millbank, London, SW1P4RG, UK \\ ${ }^{d}$ School of Science and Technology, Nottingham Trent University, Nottingham, NG11 8NS, UK \\ * Corresponding author: ALerwill@getty.edu Phone. 1310440 6237, Fax: 13104407711
}

\begin{abstract}
A modified microfading spectrometer incorporating a linear variable filter is used to investigate the wavelength dependence of fading of traditional watercolour pigments, dosimeters and fading standards at a higher spectral resolution and/or sampling than had previously been attempted. While the wavelength dependence of photochemical damage was largely found to correlate well with the absorption spectra of each material, exceptions were found in the case of Prussian blue and Prussian green pigments (the latter includes Prussian blue), for which an anti-correlation between the spectral colour change and the absorption spectrum was found.
\end{abstract}

Keywords: accelerated aging, light aging, microfading, lightfastness, light dosimeters, wavelength dependence, action spectra

\section{Introduction}

The application in museums of new lighting technologies with differing spectral power distributions means greater knowledge is required of the wavelengths that cause photochemical damage, to inform museum policy for displaying lightsensitive material. The development and application of the improved microfading spectrometer used in this study formed one strand of an extensive research effort on the practical application of anoxic framing to materials significant for the collection of British and also modern and contemporary art at Tate, London, where the work was carried out.

Research included an assessment of the degradative potential of some traditional watercolour pigments including madder on a variety of substrates, and Prussian blue, for traditional, handmade, glue-sized papers of the type used by watercolour 
artists in the so-called golden age of British watercolour c.1750-1850. The emphasis on traditional watercolour pigments was justified by their importance in Tate's collection, which includes over 36,000 works on paper (though not all are coloured) by J.M.W. Turner (1775-1851) and some 4000 works on paper by other water-colourists from the golden age in this medium, as well as the studio materials of J.M.W. Turner used until his death, a resource unique for British art at this period.

Colorants are chosen due to their absorption in the visible range. It has therefore been argued that fugitive colorants must be faded predominantly by the visible region [1]. The earliest work investigating the influence of wavelength on colour change was carried out by Russell and Abney in 1888 [2]. Exploring the effects of blue, green and red light on selected watercolours, they concluded that 'the rays which produce by far the greatest change in a pigment are the blue and violet components of white light'. This is now known to be simplistic and it is well known that UV radiation often causes more damage than visible light (e.g. Hattori et al. [3]). For this reason, most museums install filters to block out the UV radiation. Therefore, in the current study only the visible spectrum will be considered.

Appel and Smith (1928) [4] used various coloured filters to assess their effect on colour change. This technique was adopted for work in subsequent years by McLaren (1956) [1] using 5 filters which cut off radiation below 600nm, 460nm, 400nm, 360nm and 295nm, These filters were employed to divide the incident light into 5 wavebands for observation of their effect on photochemical degradation. Further investigations using either monochromatic or broad-band fading were carried out by Kenjo [5, 6], Saunders and Kirby [7] and Hattori et al. [3]. In the work by Kenjo, monochromatic light was employed to investigate the effect of radiation from $245 \mathrm{~nm}$ to $699 \mathrm{~nm}$ on 6 colorants and by this means the number of bands in the visible range was increased to seven (from $390 \mathrm{~nm}$ to 699 $\mathrm{nm})$. Saunders and Kirby used broad-band interference filters with bandwidths of 70nm (FWHM) at peak transmittances located at 50nm intervals in the visible range from $400 \mathrm{~nm}$ to $700 \mathrm{~nm}$ on blue wool standards 1 to 3 and 13 organic pigments. Hatorri et al. studied two blue wool standards using monochromatic light at $16 \mathrm{~nm}$ intervals between 220nm and 700nm in wavelength. 


\section{Materials and Methods}

The samples comprised materials used as dosimeters in the cultural heritage sector and historically accurate reconstructions of fugitive traditional watercolour pigments.

Light dosimeters and standards were selected to represent dosimeters either proposed decades ago [8], and since then regularly used by museums and galleries to assess light exposure (ISO Blue Wool Standards, see British Standard 1006:1978) [9] or recently proposed for the purpose (Lightcheck ${ }^{\circledR}$ Sensitive and Ultra). Blue Wools $1 \& 2$ are a combination of Eriochrome 2 Azurole B (colour index (CI) 43830) \& Indigosol Blue AGG (CI 73801) dyed onto wool. Lightcheck ${ }^{\circledR}$ Sensitive and Lightcheck ${ }^{\circledR}$ Ultra are two highly sensitive light dosimeters (constructed from a calibrated light sensitive coating printed on glass and paper respectively) developed and refined by the LiDo project; a collaboration between a number of European research institutes [10].

Litharge and Rhodamine $\mathrm{B}$ were 2 simple dosimeters for monitoring light exposure in galleries as suggested by Kenjo [5] and these were recreated: litharge was mixed with a $10 \%$ aqueous solution of animal glue in order to make a soft paste and then applied to paper board. A $0.3 \%$ solution of Rhodamine B was mixed with alcohol and a cotton-based blotting paper was immersed in the solution and dried in a dark room.

All the dry pigments were prepared by grinding with gum Arabic, diluting with distilled water and applied by brush onto paper specified and created for the research [11] to simulate the white papers often used by Turner and his contemporaries: gelatine-sized and glazed paper containing approximately 60\% lincell (cellulose from flax) and 40\% long cotton linter, made at Ruscombe Mill, France. Prussian blue (Tate Gallery Archive 7315.6\#6, Q04047 TTB6) and madder (Tate Gallery Archive 7315.6\#13, Q04047 TTB13) were obtained from J.M.W. Turner's studio materials used until his death in 1851. Small samples of watercolour cakes made from Prussian green and dragon's blood pigments, from an Ackermann paint box dated 1796-1826, were mixed with water before painting 
out on the same paper. Painted-out samples of weld and litmus, produced as historically accurate reconstructions by Saunders and Kirby [7], used for earlier wavelength-dependent fading experiments and generously made available by them for this study had already been ground in gum Arabic, diluted with distilled water and applied in a thin wash on Whatman silversafe conservation grade paper. These samples were their control samples which had been kept in the dark since they were painted out.

Micro-fading spectrometers typically employ a high-powered continuous-wave xenon light source (in this case Ocean Optics HPX2000) connected directly to a solarisation resistant optical fibre with a 600 micron fibre core [12]. The end of this fibre is connected to a confocal probe designed for this task, containing two lenses (matched achromatic pairs optimized for the visible region). Light passes through an extended hot mirror utilized to remove the infrared in order to reduce temperature and the ultraviolet to better simulate the museum environment. The filtered light is focused to a $0.25 \mathrm{~mm}$ spot over the entire wavelength range of 400 to $700 \mathrm{~nm}$.

In order to monitor colour change in real time, scattered light from the small sample area is returned to the optical system via another optical probe of the same design at 45 degrees to the normal, which is a standard geometry for colour measurement [13]. Sampled radiation then passes through a neutral density filter to avoid saturation of the spectrometer CCD detector (Avantes Avaspec 2048) which receives this signal via an optical fibre, and the software (AvaSoft 7.0) analyses change in the spectrum and the degree of fading.

The monitored spectrum is converted into CIE $1976 \mathrm{~L}^{*} \mathrm{a}^{*} \mathrm{~b}^{*}$ colour space and calculated for the $2^{\circ}$ standard observer under CIE standard illuminant D65 to provide an automated calculation of colour difference of the fading spot. This colour space has chromaticity coordinates of $L^{*}, a^{*}$ and $b^{*}$. The $L^{*}$ value represents luminance and values range from 0 for black to 100 for white. The a* and $\mathrm{b}^{*}$ values represent coordinates on the axis moving from red to green $\left(+\mathrm{a}^{*}\right.$ to $a^{*}$ respectively) and yellow to blue ( $+b^{*}$ to $-b^{*}$ respectively). The unit of colour 
difference is represented by $\Delta \mathrm{E}^{*}{ }_{a b}$ which can be calculated as the Euclidian distance between 2 locations within the colour space.

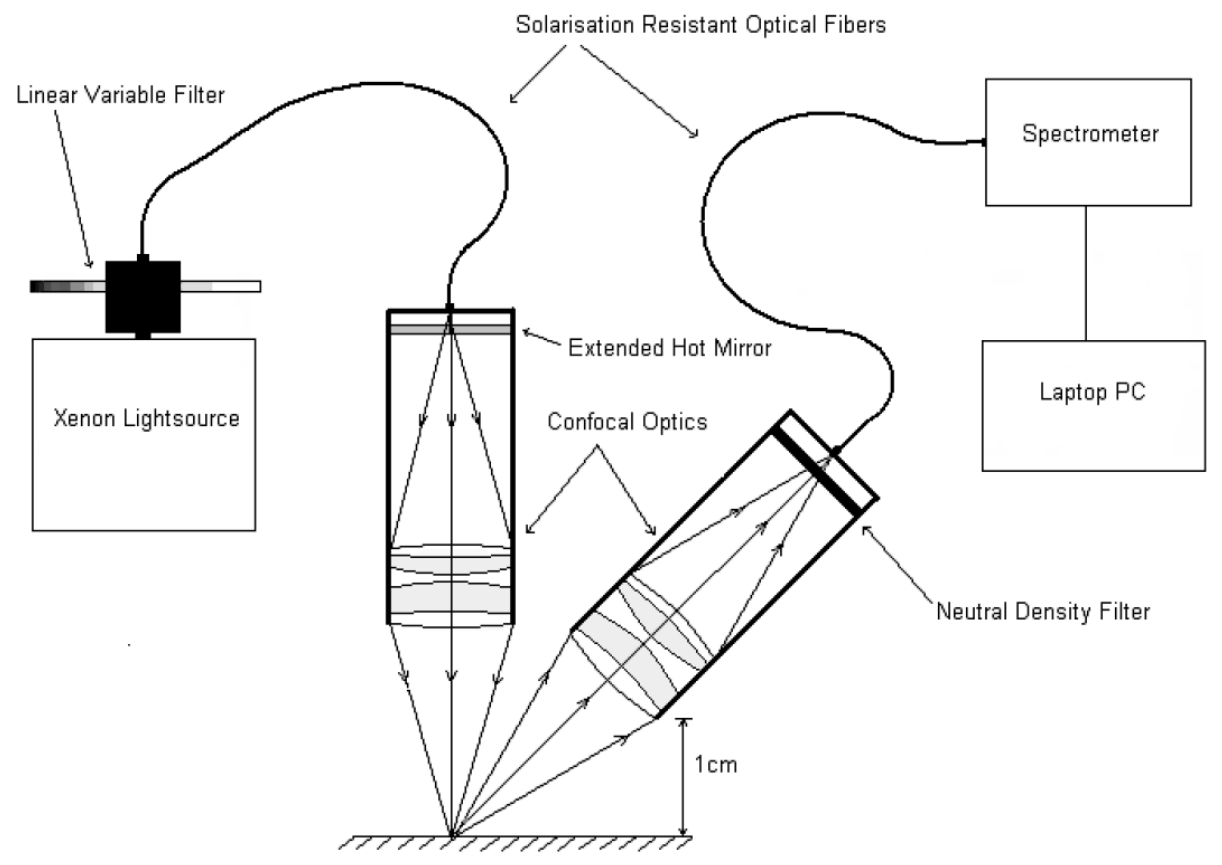

Fig. 1 Schematic representation of the wavelength tuneable microfading spectrometer with linear variable filter

The micro-fading spectrometer (with the addition of a linear variable filter) can be seen in Fig. 1 and is discussed in more detail in a previous publication [12]. The xenon lamp is filtered with an Ocean Optics LVF-UV-HL or LVF-HL linear variable interference filter. The filter bandwidth of this technique is 20 to $30 \mathrm{~nm}$ FWHM and it is possible to vary the central wavelength of the filter in the visible range.

The incident power was measured using a Melles Griot integrated 2 Watt broadband power and energy meter system integrating over the wavelength range $200 \mathrm{~nm}$ to $20 \mu \mathrm{m}$. The incident power measured in the absence of the variable filter but with the filter holder in place is $1.46 \mathrm{~mW}$ or 0.46 lumens at focus. Because of the filter holder, the coupling efficiency of light from the lamp into the fibre has been reduced and power output from the system is smaller than the version of the instrument without the variable filter holder. The unfiltered instrument produces $2.59 \mathrm{~mW}$ or 0.82 lumens $\left(1.7 \times 10^{7}\right.$ lux for a $0.25 \mathrm{~mm}$ focused spot). The unfiltered 
relative power spectrum of light incident on the sample measured using a calibrated spectrometer is shown in Fig. 2.

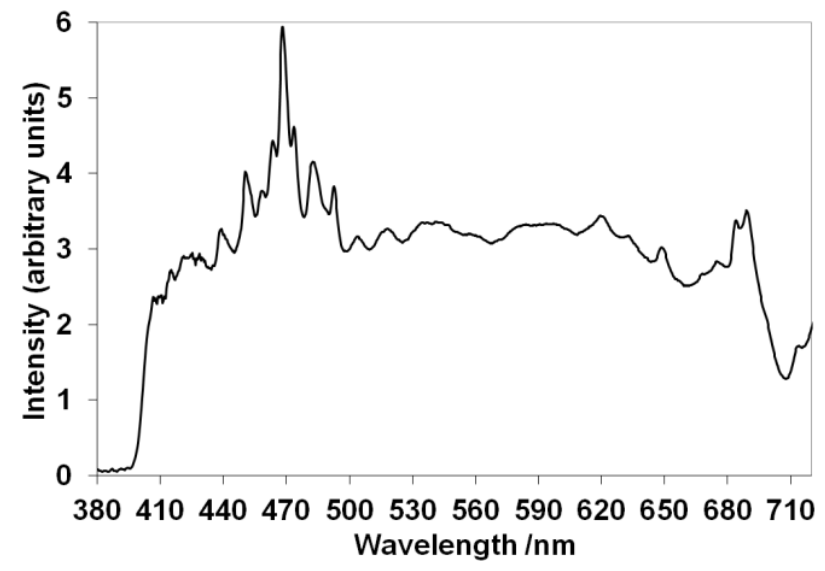

Fig. 2 The relative power spectrum of incident radiation used in broad spectrum fading tests

Each sample is individually exposed to 13 wavelength peaks at a new location each time. Figure 3 shows the relative power output at each wavelength. The length of time for fading was altered at each wavelength accordingly to compensate for the variation in incident power with wavelength caused by the spectral power distribution of the lamp and varying transmission of the filter. The majority of the samples were illuminated with the equivalent of approximately 3.5J of total energy at each of the 13 wavelengths.

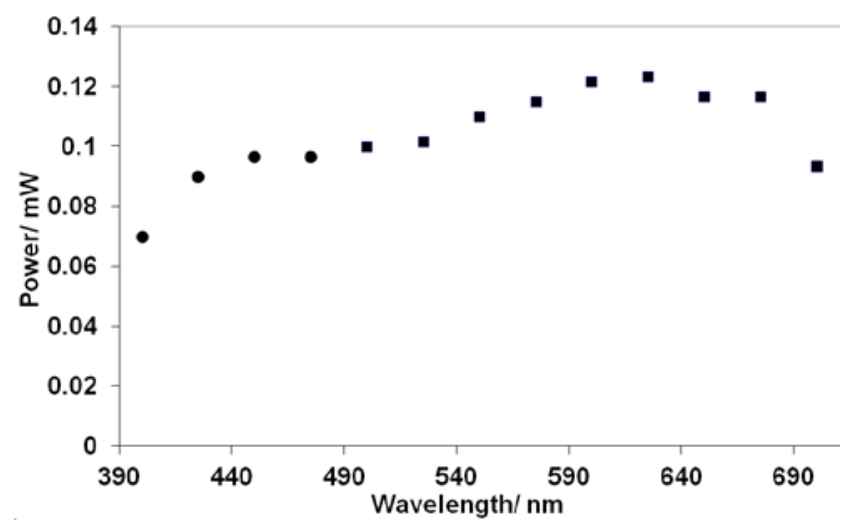

Fig. 3 The incident power variation at focus of the wavelength tuneable microfading spectrometer, with an Ocean Optics LVF-UV-HL filter (from 405nm to 475nm) and an LVF-HL filter (from $500 \mathrm{~nm}$ to $700 \mathrm{~nm}$ ) in place

With the linear variable filter in place, the temperature measured by a thermocouple substituted for the sample was found to increase by approximately $1^{\circ} \mathrm{C}$ independent of wavelength range. No alteration was observed when focusing 
on a liquid crystal thermometer with temperature increments of $2^{\circ} \mathrm{C}$. Work was conducted at approximately $21^{\circ} \mathrm{C}$ and at a relative humidity of $45 \% \pm 5 \%$.

After an initial reading has been taken, the tuneable filter is adjusted to the chosen wavelength prior to fading. The filter is then removed after fading to take a spectral measurement. Due to the presence of the tuneable filter, colour measurements are not possible during fading unless the tuneable filter is removed and a measurement made with a neutral density filter significantly reducing the intensity to the illumination probe to avoid significant degradation in the case of very fugitive materials. A full spectrum must be recorded before and after fading in order to obtain a value for the colour difference.

The error caused by the removal and addition of the neutral density filter was found to have a mean $\Delta \mathrm{E}^{*}{ }_{a b}$ of $\sim 0.3$ when measured 10 times using a stable white standard (barium sulphate) as the sample. Other major source of measurement error is drift in the system which contributed an error no greater than $0.3 \Delta \mathrm{E}^{*}{ }_{\mathrm{ab}}$ using the same stable white standard

Table 1 provides a summary of the sample type in the first column and total incident energy at each wavelength in the second column.

\begin{tabular}{|c|c|}
\hline Name of sample & $\begin{array}{c}\text { Total incident energy per } \\
\text { filter location (J) }\end{array}$ \\
\hline $\begin{array}{c}\text { Bluewool } 1 \\
\text { (standard material) }\end{array}$ & 3.5 \\
\hline $\begin{array}{c}\text { Bluewool } 2 \\
\text { (standard material) }\end{array}$ & 5.25 \\
\hline $\begin{array}{l}\text { Lightcheck }^{\circledR} \text { Ultra } \\
\text { (standard material) }\end{array}$ & 0.1 \\
\hline $\begin{array}{l}\text { Lightcheck }^{\circledR} \text { Sensitive } \\
\text { (standard material) }\end{array}$ & 0.3 \\
\hline $\begin{array}{c}\text { Rhodamine B } \\
\text { (fluorescent dye) }\end{array}$ & 3.5 \\
\hline $\begin{array}{c}\text { Litharge } \\
\text { (inorganic yellow pigment) }\end{array}$ & 3.5 \\
\hline $\begin{array}{c}\text { Madder } \\
\text { (laked, organic pink pigment) }\end{array}$ & 3.5 \\
\hline $\begin{array}{c}\text { Dragon's blood } \\
\text { (unlaked, organic red/brown pigment) }\end{array}$ & 3.5 \\
\hline $\begin{array}{c}\text { Weld } \\
\text { (laked organic yellow pigment) }\end{array}$ & 3.5 \\
\hline $\begin{array}{c}\text { Litmus } \\
\text { (organic pigment) }\end{array}$ & 1.75 \\
\hline
\end{tabular}




\begin{tabular}{|c|c|} 
Prussian green & \\
(mixture of Prussian blue and a yellow pigment) & 3.5 \\
\hline $\begin{array}{c}\text { Prussian blue } \\
\text { (organometallic blue pigment) }\end{array}$ & $1.75 \& 3.5 \& 5.25$ \\
\hline
\end{tabular}

Table 1 List of samples and the corresponding total incident energy at each of the 13 individual fades at different wavelengths

\section{Results and discussion}

Colour changes versus the wavelength of incident radiation with the corresponding reflection spectra presented on the inverted y axis are shown in figures 4 to 8.
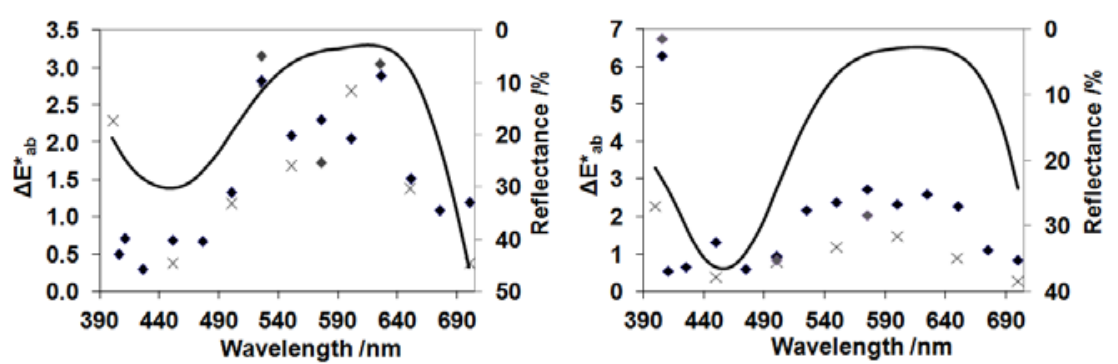

Fig. 4 Colour change $\Delta \mathrm{E}^{*}{ }_{\mathrm{ab}}$ versus wavelength of incident radiation for ISO Blue Wool 1 (left) and 2 (right). The diamonds are from this study (grey diamonds were repeat measurements) and the crosses are from previous work by Saunders and Kirby (1994) scaled down by a factor of 10 to fit into the same graph. The solid curves represent the initial reflectance spectra in inverted reflectance scale

The Blue Wool results shown in Fig. 4 indicate that they are most sensitive between approximately 500nm and 650nm. Previously, Blue Wool 1 and 2 were assessed by McLaren [1] and Saunders and Kirby [7] with comparable results. Both reported peaks at $600 \mathrm{~nm}$ in the red region, however, McLaren reported no significant colour change in the blue end of the spectrum whereas Saunders and Kirby reported an equal or greater colour change than that seen at $600 \mathrm{~nm}$. Hattori [3] have reported on the response of AATTC Blue wool standard L2 made from the same dyes, they noted the same peak in the action spectrum (colour change versus wavelength of incident radiation) at around $625 \mathrm{~nm}$, however far more intense peaks at $245 \mathrm{~nm}$ and $295 \mathrm{~nm}$ were found, not relevant here since the samples were not exposed to the ultraviolet. 
The micro-fading measurements confirmed significant colour change in the red region in the case of Blue Wool 1 and confirmed McLaren's results by showing no considerable change in the blue region. A greater colour change was observed at $405 \mathrm{~nm}$ in the case of Blue Wool 2 with microfading.
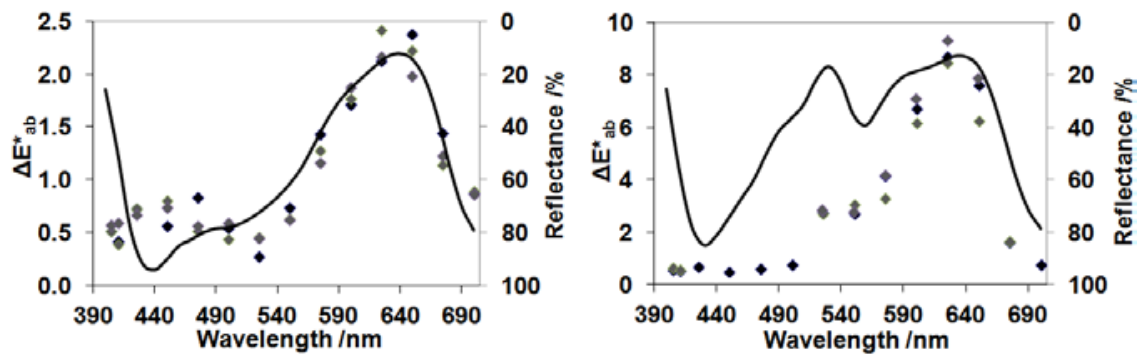

Fig. 5 Colour change $\Delta \mathrm{E}^{*}$ ab versus wavelength of incident radiation (diamonds) for Lightcheck ${ }^{\circledR}$ Sensitive (left) and Lightcheck ${ }^{\circledR}$ Ultra (right). The grey diamonds are for repeat measurements. The solid curves represent the initial reflectance spectra in inverted reflectance scale.

The peak colour change is around 600-650nm for both Lightcheck ${ }^{\circledR}$ Sensitive and Lightcheck ${ }^{\circledR}$ Ultra (Fig. 5). The action spectra of the Lightchecks correspond roughly to the inverse of their reflectance spectrum, similar to the case of the blue wool samples (Fig. 4).

The widely used Blue Wool standards and Lightcheck dosimeters were more vulnerable to the longer wavelength regions of the visible spectrum (as has previously been found).

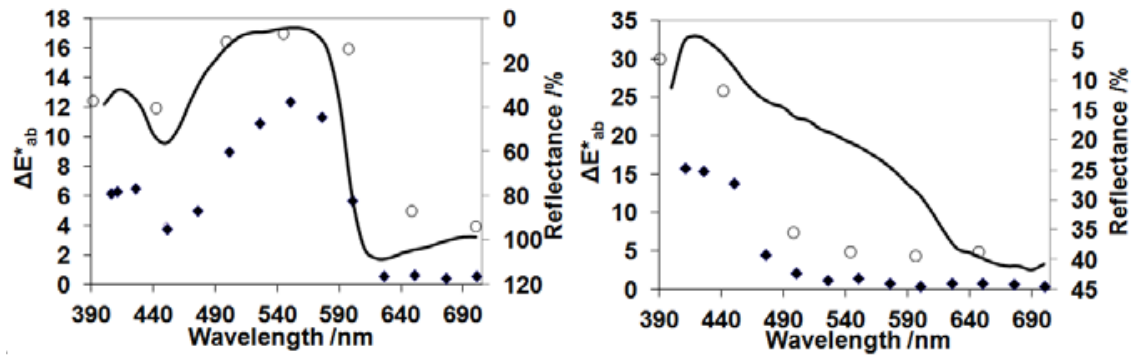

Fig. 6 Colour change $\Delta \mathrm{E}^{*}{ }_{\text {ab }}$ versus wavelength of incident radiation for rhodamine $\mathrm{B}$ (left) and litharge (right). The diamonds are from this study and the circles are from previous work by Kenjo (1986). The solid curves represent the initial reflectance spectra in inverted reflectance scale

The action spectra of the two simple dosimeters, rhodamine B and litharge suggested by Kenjo [5] are shown in Fig. 6. The results of the present study agrees with previous the results obtained with monochromatic light. The action spectra also correspond roughly with the absorption spectra. 
None of the 6 dosimeters studied have a constant $\Delta \mathrm{E}^{*}{ }_{\mathrm{ab}}$ as a function of the wavelength of the incident radiation. LightChecks are the worst as dosimeters in the visible range as their action spectra have rather sharp peaks around 600$650 \mathrm{~nm}$.
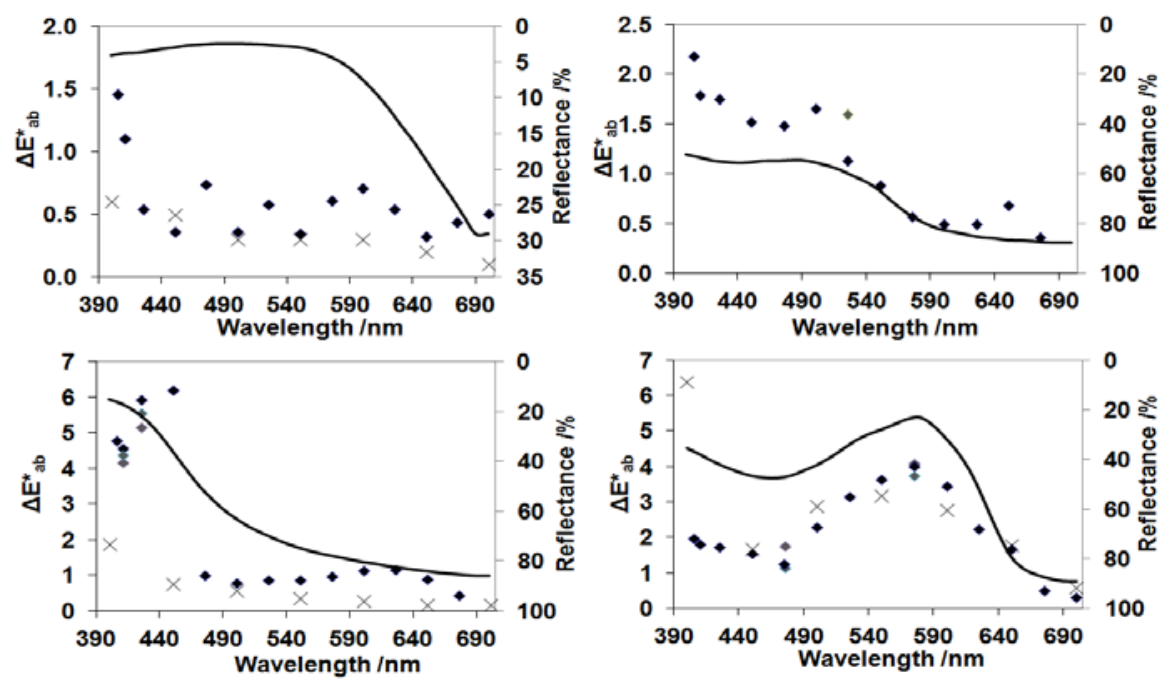

Fig. 7 Colour change $\Delta \mathrm{E}^{*}{ }_{\mathrm{ab}}$ versus wavelength of incident radiation for madder (top left), dragon's blood (top right), weld (bottom left) and litmus (bottom right) compared to previous research with wavelength dependent artificial ageing. The diamonds are from this study (grey diamonds are for repeat measurements) and the crosses are from previous work by Saunders and Kirby (1994) scaled down by a factor of 10 to fit into the same graph. The solid curves represent the initial reflectance spectra in inverted reflectance.

The action spectra of dragon's blood and two lake pigments (organic pigments prepared by adsorption of an organic dyestuff onto an inorganic substance such as alum), madder and weld, are shown in Fig. 7. The madder lake sample studied by Saunders and Kirby [7] was prepared by them but the madder sample used in this study was from Turner's studio materials. However, despite the difference in the samples, the action spectra of madder in this study agrees with that of Saunders and Kirby [7]. The action spectra are likely to be dominated by the degradation of the main dye component of madder lake pigment common between the two samples. Similar to the dosimeters, the action spectra of the pigments roughly follow the absorption spectra, indicating that in these cases the light absorption causing the degradation process is independent of the energy of the radiation in the visible range. In the case of weld and litmus, the same samples were studied by Saunders and Kirby [7]. A comparison with the present study shows that the 
general trend agrees in each case, though no strong colour change was detected in litmus at $400 \mathrm{~nm}$ in this study. The difference may be due to the broader bandwidth of the filters used by Saunders and Kirby [7].
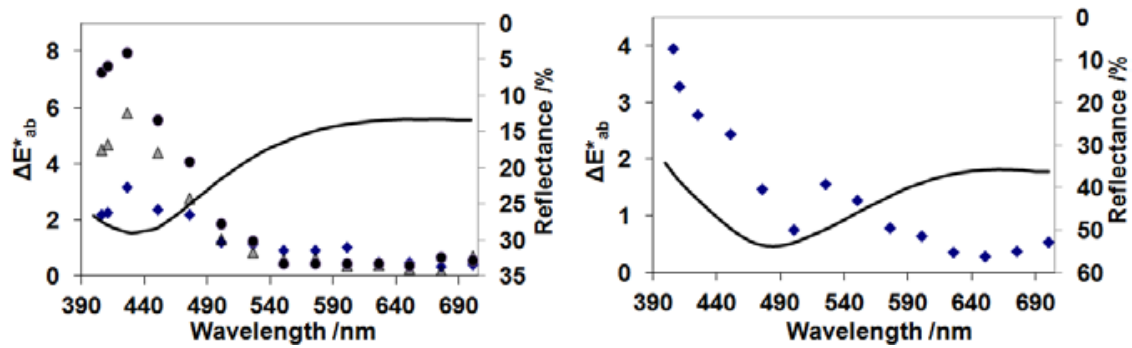

Fig. 8 Colour change $\Delta \mathrm{E}^{*}{ }_{\mathrm{ab}}$ versus wavelength of incident radiation for TTB6 Prussian blue (left) for a total exposure over all wavelengths of a 20, 40 and 60 minute period (shown as diamonds, triangles and filled circles respectively) and Prussian green (right) for an exposure of 40 minutes (shown as diamonds). The solid curves represent the initial reflectance spectra in inverted reflectance scale

The action spectra for Prussian blue and Prussian green (which contains Prussian blue and an organic yellow pigment not characterised in detail but possibly gamboge) are shown in Fig. 8. Both are most sensitive at the blue part of the spectrum $(<500 \mathrm{~nm})$. In the case of Prussian blue, the action spectrum peaks at 425nm independent of total incident energy. Contrary to all the other samples, the Prussian blue action spectrum has the exactly opposite trend to the absorption spectrum. In the case of Prussian green, the action spectrum follows the trend of the absorption spectrum up to 500nm, as is expected if its yellow component is fugitive, but at longer wavelengths the action spectrum has an opposite trend to the absorption spectrum similar to that of Prussian blue.

Prussian blue is a type II mixed valence transition metal complex; ferric ferrocyanide, iron (III) hexacyanoferrate (II) conventionally represented as $\mathrm{Fe}_{4}\left[\mathrm{Fe}(\mathrm{CN})_{6}\right]_{3} \cdot \mathrm{n} \mathrm{H}_{2} \mathrm{O}$ (where $\mathrm{n}$ is 14-16). This is known as 'insoluble' Prussian blue. The general formula $\mathrm{M}^{\mathrm{I}} \mathrm{Fe}^{\mathrm{III}} \mathrm{Fe}^{\mathrm{II}}(\mathrm{CN})_{6} \cdot \mathrm{n} \mathrm{H}_{2} \mathrm{O}$, where $\mathrm{M}^{\mathrm{I}}$ is a potassium $\left(\mathrm{K}^{+}\right)$, ammonium $\left(\mathrm{NH}^{4+}\right)$ or sodium $\left(\mathrm{Na}^{+}\right)$ion (depending on the method of manufacture), and $n=14-16$ could be considered more correct [14]. It has been observed to lose colour in the absence of oxygen and regain all or most of its colour on re-exposure to air $[1,15,16]$. The same effect has been observed in strong light, in air $[17,18]$. The chemistry of the degradation process is still not 
very well understood. The action spectrum may help to understand the lightinduced degradation process of Prussian blue.

\section{Conclusions}

This work with measurements at higher wavelength resolution and/or intervals than previous studies strongly supported many previous assertions that the wavelength dependence of fading in the visible wavelength range correlates well with the absorption spectrum of the colorant. Exceptions found here are Prussian blue and Prussian green (the later contains Prussian blue pigment). In the case of Prussian blue, fading appears to be anti-correlated with the pigment's absorption spectrum, possibly due to the anomalous fading behaviour already noted. There is an apparent cut off at approximately 550nm. Below this wavelength Prussian blue photo-degradation occurs, and the redox reactions that define the anomalous reversible colour change of this pigment occur. Prussian blue fading behaviour in response to full-spectrum microfading is discussed elsewhere [19] and will be discussed in detail in a future publication.

\section{Acknowledgements}

The anoxic framing project was funded 2006-09 by the Public Sector Research Exploitation Fund (third round) and was supported by Tate. Charlotte Caspers who sourced materials and prepared the historically accurate reconstructions at Tate in 2008 was funded by the Prins Bernhard Cultuurfonds and supported by Stichting Restauratie Atelier Limburg during her masters research at the University of Amsterdam, all in the Netherlands. Anna Brookes was funded by the AHRC Professional Preparation Research Masters Scheme, University of the Arts, London, UK. Thanks also to David Saunders and Jo Kirby for their help and cooperation.

\section{References}

[1] K. McLaren, J, Soc. Dyers. Colour. 72, 86 (1956)

[2] W. Russell, W. de Abney, Report to the Science and Art Department of the Committee of Council on Education (HMSO, London, 1888)

[3] H. Hattori, K. Yoshizumi, P. Cox Crews, Dyes and Pigments 92, 936 (2012)

[4] W.D. Appel, W.C. Smith, Am. Dyest. Rep. 17, 410 (1928) 
[5] T. Kenjo, Int. J. Museum Management \& Curatorship 5, 295 (1986)

[6] T. Kenjo, Sci. Conserv. 26, 31 [In Japanese] (1987)

[7] D. Saunders, J. Kirby, in Preventive Conservation: Practice, Theory, and Research, ed. by A. Roy and P. Smith (London:IIC, London, 1994), p.190

[8] N. H. Tennent, J. H. Townsend, in Lighting (The Museums Association, London, 1987) p. 31

[9] British Standards Institution, Methods of Test for Colourfastness of Textiles and Leather, BS 1006: 1978. (BSI, London. 1978)

[10] A.L. Dupont, B. Lavédrine, C. Cucci, C. Loisel, and M. Bacci, Stud. Conserv. 53, 49 (2008)

[11] J. Thomas, PhD thesis, University College London, 2012

[12] A. Lerwill, J. H. Townsend, H. Liang, S. Hackney, J. Thomas, in O3A: Optics for Arts, Architecture, and Archaeology, Proc. SPIE 6618, 66181G (2007)

[13] E.I. Stearns, Color Res. Appl. 13, 64 (1988)

[14] B. Berrie, in Artists’ Pigments: a Handbook of their History and Characteristics, ed. by E.W. Fitzhugh, (National Gallery of Art, Washington, 1997), p. 191

[15] V.L, Beltran, V.J Druzik, S Maekawa, Stud. Conserv. 57, 42 (2012)

[16] J. M. del Hoyo-Meléndez, M.F. Mecklenburg, Spectrosc. Lett. 44, 113 (2011)

[17] M. Ware, in Care of Photographic, Moving Image and Sound Collections Postprints, ed. by S. Clark. (Institute of Paper Conservation, Leigh, UK, 1999) p. 115

[18] M. Ware, Cyanotype : the History, Science and Art of Photographic Printing in Prussian blue. (Science Museum, London and National Museum of Photography, Film and Television, Bradford, 1999)

[19] A. Lerwill, PhD thesis, Nottingham Trent University, 2011 